\title{
GENERATION OF BIO-BASED PRODUCTS FROM OMSW BY USING A SOLID-LIQUID SEPARATION TECHNIQUE AND AN ANAEROBIC TREATMENT
}

\author{
Jan Kannengiesser ${ }^{1, \star}$, Celina Kuhn ${ }^{1}$, Timo Mrukwia ${ }^{1}$, Daniel Stanojkovski ${ }^{2}$, Johannes \\ Jager ${ }^{1}$ and Liselotte Schebek ${ }^{1}$ \\ ${ }^{1}$ Technische Universität Darmstadt, Institute IWAR, Faculty of Civil and Environmental Engineering, Franziska-Braun-Strasse 7, \\ 64287 Darmstadt, Germany \\ 2 Jager Biotech GmbH, Roßbergweg 7b, 64380 Roßdorf, Germany
}
Article Info:
Received:
16 July 2018
Revised:
24 September 2018
Accepted:
21 November 2018
Available online:
3 December 2018
Keywords:
Carboxylic acids
Solid waste
Extraction
Chain elongation
Anaerobic fermentation
Bio-based products

\begin{abstract}
The present paper provides an overview of the investigations (involving different liquids) regarding a new technology that is able to generate valuable bio-based products by using the liquid phase from organic municipal waste as raw material. The liquids used in this study were tested and treated in different ways to find out which substrates are most suitable for the process. For the purpose of generating bio-based products from organic waste, a solid-liquid separation process was performed first. Thereafter, in order to increase the amount of non-polar fatty acids (FAs) in the liquid substrate, an anaerobic digestion process was used. However, after the digestion, most of the FAs found in the liquid substrate were polar FAs. To increase the amount of non-polar FAs further, another treatment step, "ethanol maturation", was carried out as the third step. Subsequently, the refining process was started with the extraction of the FAs from the liquid substrate by using a non-polar extraction solvent, such as Oleic acid methyl ester (OME). At this point, "extractive digestion" takes place. The FAs can be extracted over a longer period of time and during the digestion. As a result, the amount of longer-chain fatty acids in the OME increases. After re-extracting the FAs from the solvent, a transesterification process was used to produce fatty acid ethyl esters, which can be sold as cleaners or solvents to the metal industry for surface treatment. The production of other bio-based products, such as lubricants, fuels and polymers, is also possible. The following five substrates were mainly used for the investigations: (1) a liquid phase from organic municipal waste, produced by a percolation process; (2) fresh percolate from German kitchen waste; (3) percolates of different stages from a digestion plant in Germany; (4) old leachate from German landfills; and (5) young landfill leachate or leachate from pressed municipal solid waste, which was used to imitate African waste. These substrates were treated using the method described above. The results show that young landfill leachate has the highest potential. The highest availability of FAs occurs after biological pre-treatment of percolates. For this reason, very fresh percolates hardly contain any fatty acid. They must first be generated by the biological degradation of the organic ingredients.
\end{abstract}

\section{INTRODUCTION}

In 2016, the amount of waste produced by households in Germany was 46,6 million tonnes. Around ten million tonnes of these wastes were classified as biological waste (including garden and park waste) (Destatis, 2018a). Biological wastes are also produced in different industrial sectors. In 2016, about 4,4 million tonnes of biological wastes were collected separately in households (Destatis, 2018a).
The amount of the collected biological waste is estimated to increase since 1 January 2015 (Krause et al., 2014). As of this date, the Kreislaufwirtschaftsgesetz (KrWG) contains the German implementation of the EU Waste Framework Directive into national law. The law enforces the change in the collection system of biological waste from voluntary to obligatory, $\S 11 \mathrm{KrWG}$ (BmJV, 2012). These wastes can still be recycled or used to generate energy. At the moment, the dominant waste treatment method is 
composting. Presently, separately collected bio-waste is typically recycled in a composting or anaerobic digestion (AD) system, producing compost (or digestate) as fertilizer and soil conditioner, and in the case of AD biogas as renewable energy (Andreottola et al., 2012; Edwards, 2015). However, in the near future, other forms of high-value bio-waste recycling methods, such as the production of bio-products and chemicals in bio-refineries, are expected to also be available in the market (De Jong et al., 2012). The new idea of using biodegradable waste is meant to combine a composting plant with a facultative anaerobic treatment step. Organic acids carry the main part of the energy content of biomass at the early stage of anaerobic digestion process and are easy to transfer into liquid products by further biorefinery steps. After the extraction of organic acids, the residual waste can be transported to the composting plant to generate high quality compost. Based on the separate collection of the different waste fractions, a new biotechnology focusing on the special requirements for these kinds of waste can be developed.

Biogenic waste is not only produced in the waste management sector but also in the agricultural sector. More than 56,4 million tonnes of agricultural waste are generated every year in Germany (Destatis, 2018b). These wastes are also treated by composting or mainly digestion. Based on the new law for renewable energy in Germany, the treatment of agricultural waste is getting more and more expensive, because co-financing of treatment facilities was changed by the law. Also, in the agricultural sector, innovations are needed in order to make the treatment processes more efficient (economical).

In developing countries, other suitable substrates are fresh landfill leachate and the water obtained by pressing the collected waste (Mahmud et al., 2012). It is common knowledge that developing countries are still deprived of sanitary landfills and still do not employ the multi-barrier system. The waste is not pre-treated, and there are no covers used to protect the environment from greenhouse gases (GHG) emissions and hazardous substances. Even today, nearly all municipal solid waste (MSW) is just landfilled in developing countries, like Morocco. Waste analyses have shown that the landfilled waste contains a high amount of water, $50-70 \mathrm{wt} \%$ of landfilled MSW (Smahi et al., 2013). This high amount of water leads to the generation of an enormous amount of landfill leachate. In this research, young landfill leachate and the water obtained by pressing the collected waste will be tested as substrate for the new technology.

The application of the new integrated technology in developing countries could help to minimise the problem of landfill leachate production and create a new platform for industrial bio-based chemicals.

\section{MATERIALS AND METHODS}

In this chapter, the processes involving the different liquid wastes are described. In the first subsection, the investigations in Germany are presented, while the subsequent subsection shows the treatment process using typical waste from Africa.

\subsection{Investigations with biological waste from Ger- many}

This chapter describes the generation of non-polar fatty acids from organic waste and the investigations into the production of bio-based products from this type of fatty acid. Four of the five substrates were directly made out of biological waste from Germany. Two of them were based on the biological wastes from Darmstadt, which were collected from private households and treated at the composting facility in Darmstadt. One of them was obtained from biological waste from the digestion plant in Lemgo. By these examples, the different treatment stages were sampled. The last one originated from German landfills and was taken directly on site.

\section{Medium 1: Biological waste from a composting facility}

The first experiments were performed from 2012 to 2014. These experiments served as reference experiments for the subsequent tests. Based on these data, the processes were extended and other liquids were treated.

As a first step, a solid-liquid separation process was integrated into the existing treatment concept of the composting facility in Darmstadt. The separation of the liquid and the solid phases took place in a modified rotting box. This rotting box was equipped with a percolation system, which allowed repeated percolation of the liquid phase of bio-waste from the solid phase in order to transfer the majority of the organic compounds from the solid phase to the liquid phase. Next to the percolation system, the rotting box was also equipped with a special air circulation system that allowed not only the injection of fresh and circulating air through the bio-material but also the injection of exhaust air collected from other rotting boxes. The schematic diagram of the rotting box is shown in Figure 1.

These modifications led to the creation of facultative anaerobic conditions in the box and the acidification of the bio-substrate. After the percolation process, non-polar fatty acids (FAs) were found in the liquid phase (Kannengießer, 2015).

To increase the amount of non-polar FAs in the liquid substrate, an anaerobic digestion process was used.

The treatment involved the digestion of the liquid phase in the modified rotting box by starting the aeration with warm exhaust air from other rotting boxes. The exhaust air had a temperature of 55 to more than $60^{\circ} \mathrm{C}$. By storing the liquid phase in intermediate bulk containers (IBC) in the rotting box, an anaerobic digestion process started, and the organic fraction in the liquid substrate was degraded into carboxylic acids.

Even after digestion, the FAs found in the liquid substrate were mostly polar FAs. To increase the amount of non-polar FAs once more, a treatment step called "ethanol maturation", which involves the addition of ethanol, was carried out next. Some anaerobic bacteria, such as Clostridium Kluyveri, can convert polar FAs to non-polar FAs by using ethanol and polar FAs for its anaerobic energy metabolism. The reaction of the process is shown in Equation 1. 


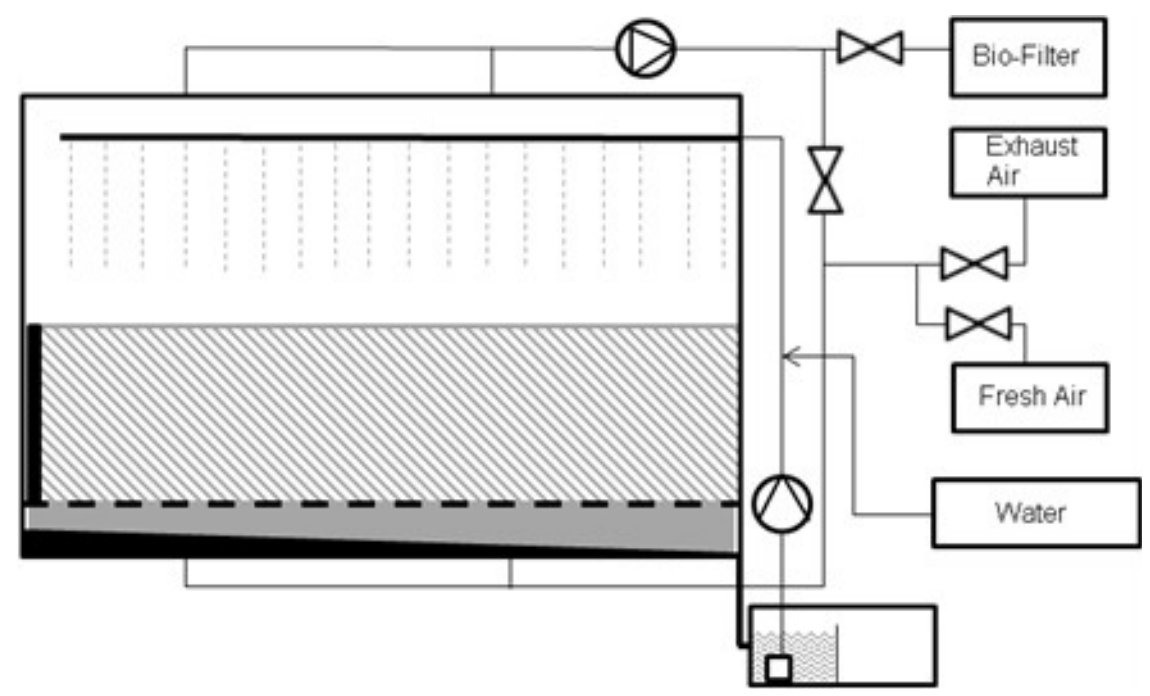

FIGURE 1: Schematic diagram of the modified rotting box (Kannengiesser, 2015).

Reaction of acetic acid and ethanol to produce hexanoic acid and water (Levy et al., 1981):

$$
2 \mathrm{CH}_{3} \mathrm{CH}_{2} \mathrm{OH}+\mathrm{CH}_{3} \mathrm{COOH} \rightarrow \mathrm{CH}_{3}\left(\mathrm{CH}_{2}\right) 4 \mathrm{COOH}+2 \mathrm{H}_{2} \mathrm{O}
$$

After the ethanol maturation process, a liquid substrate of bio-waste with a high content of non-polar FAs was transported to a refinery.

Based on the low water solubility of the non-polar FAs, which increases with the length of the carbon chain of the $F A$, there is a specific acid concentration in the liquid substrate of bio-waste above which the production of non-polar FAs stops (Kannengießer, 2015).

The microorganisms are no longer producing medium chain fatty acids (MCFA) from short chain ones because of the saturation. In order to find a solution to this problem as well as increase the generation of non-polar FAs, an extraction solvent was added during the processes of digestion and ethanol maturation. By adding the extraction solvent, the non-polar FAs were directly extracted, thereby avoiding saturation, and the microorganisms could go on with the production of non-polar FAs from polar ones. This process is called "extractive digestion". The treatment process of the bio-waste in order to generate bio-based products is described in Figure 2.

\section{Medium 2: Kitchen waste}

This medium was made of the liquid phase of kitchen waste. It originated from restaurants, schools and canteens in Darmstadt, Germany. For the liquid-solid separa- tion process, some waste bins were filled with this biological material and simply separated by tipping over of the bins into solid and liquid phases. This separation process is shown in Figure 3.

As a result, wastes with various colours and phases were generated from the unseparated waste components. Figure 3 shows the distinctions clearly. The treatment processes were conducted with a liquid volume of 4 to 9 litres.

\section{Medium 3: Biological waste from a digestion plant}

The liquid samples were taken from different treatment steps of a digestion plant in Germany. In particular, the aim was to find out which step had the highest fatty acid potential. Therefore, liquid samples were taken from the pre-rotting stage and after the fermentation process.

\section{Medium 4: German Landfill Leachate}

Three different landfill leachates from Germany were sampled. According to the Council Directive on the landfill of waste in Germany, usually, mineral and inert materials are deposited. This means that only a small amount of organic material is deposited on the landfills. The samples were taken before the leachate treatment step.

\subsection{Investigations with Substrate from developing countries}

The investigation with substrate from developing countries also took place in Darmstadt. In small-scale tests, landfill reactors with a total volume of 120 I were simulated. Although the waste was also taken from the solid

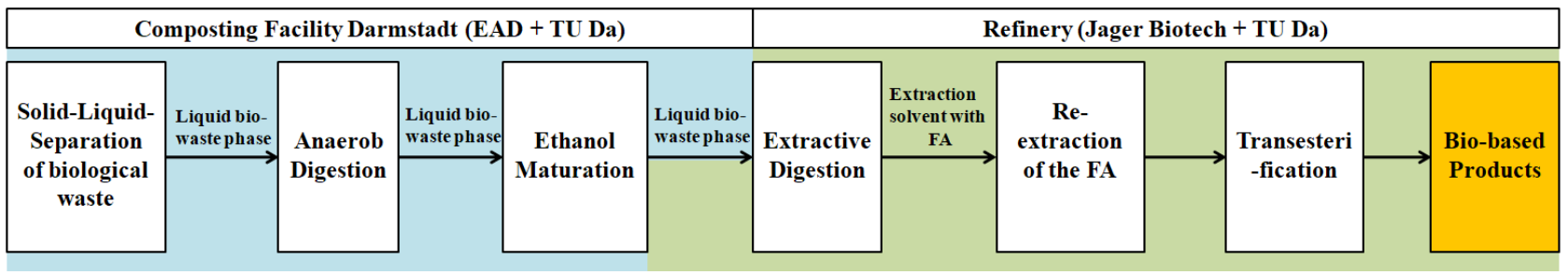

FIGURE 2: The "bio-waste to bio-based products" stream. 

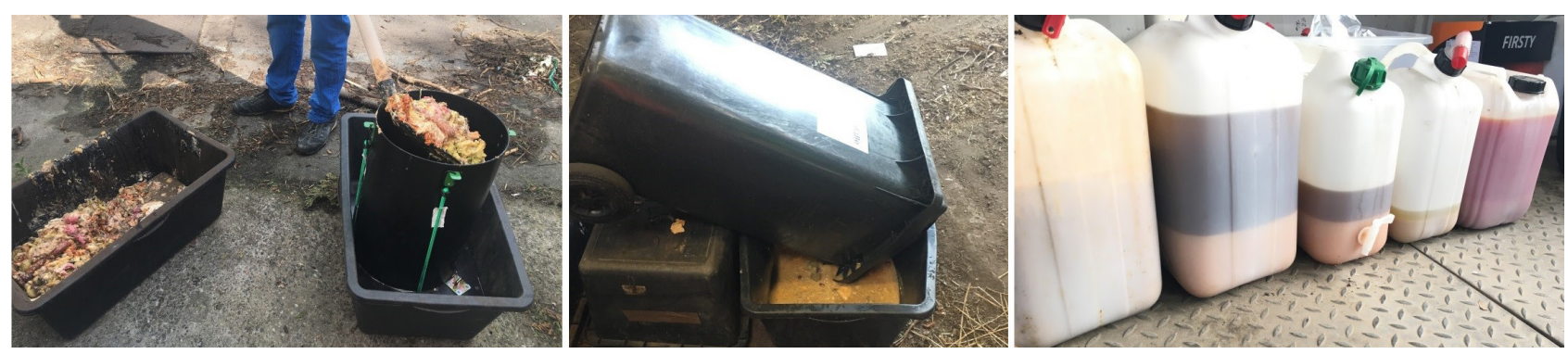

FIGURE 3: Treatment of the kitchen waste to get the liquid phase.

waste of this city, it was adapted to have the composition of waste from Morocco. Approximately $90 \%$ of the waste could be installed in one reactor. After the airtight sealing of the reactors, they were always stored at a temperature of around $38^{\circ} \mathrm{C}$ in a test container.

Afterwards, the fermentation process started under anaerobic conditions. A sketch of a reactor cross-section is shown in Figure 4. A system was used to simulate in every reactor the constant compressive stress in a landfill site. The leachate was removed regularly by means of a valve (Medium 5). In order to simulate rainfall events, liquids were added to the system via a lockable opening. The gas was always collected outside the container in an air bag.

\subsection{Post-treatment of the different mediums}

The post-treatment of all the liquids were based on the first experiments (described in 2.1). In accordance with this, further maturing and extraction took place after the separation of the liquid phase. About 4 to 10 litres of the liquids were stored in an extra canister at a temperature below $38^{\circ} \mathrm{C}$. The ethanol maturation was carried out by the addition of ethanol gotten from the percolation process, as described above in the previous experiments. The chain elongations proceeded according to the reaction in Equation 1. One week after the extractive digestion started, longer-chain fatty acids could be extracted by adding the extraction medium, Oleic acid methyl ester (OME). Also, in this case, two different post treatment methods were applied, the punctual extraction and the new extractive digestion.

\subsection{Refining process}

The refining process commenced with the extraction of FAs from the liquid substrate by using a non-polar extraction solvent. Two different extraction solvents were tested. First, a vegetable oil fuel, made out of used kitchen oil, was used to extract MCFA. The problem of this extraction solvent is that it changes composition. The change in composition of the extraction solvent is dependent on the used kitchen vegetable oil. This makes it nearly impossible to analyse the extracted MCFA in the solvent, because the method of analysis has to be optimised to the composition of the extraction solvent. Considering this, in 2015, another

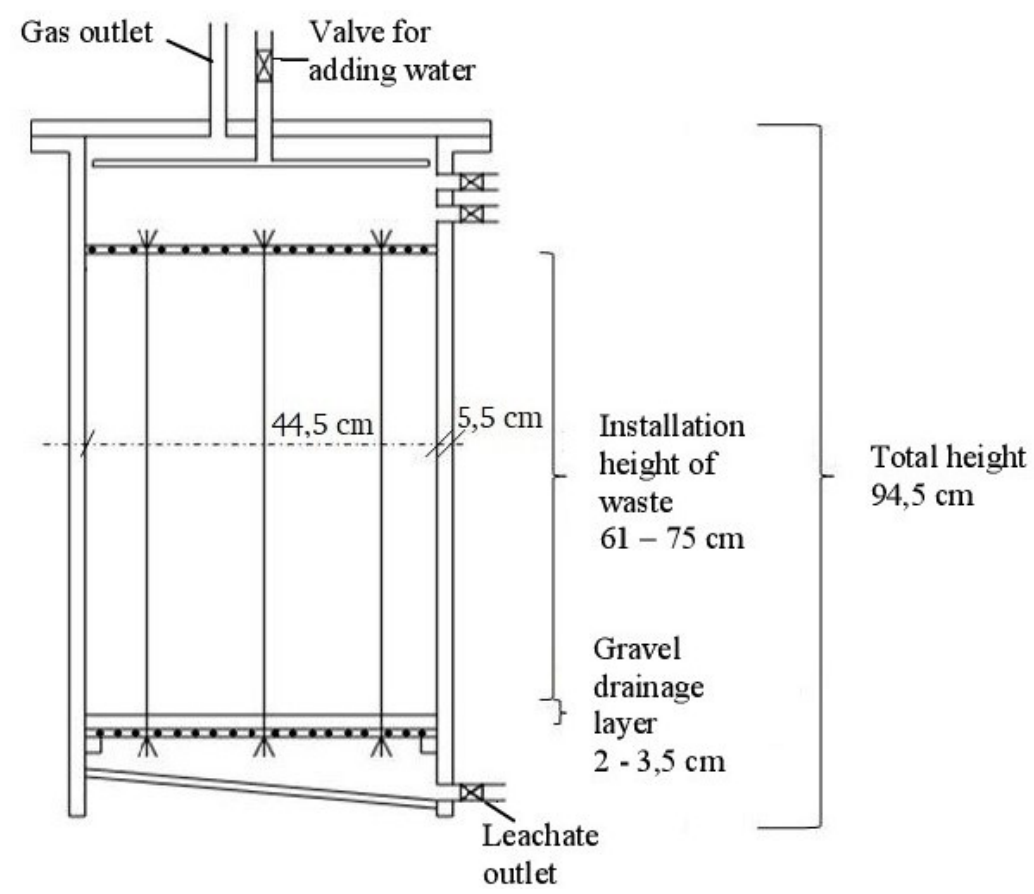

FIGURE 4: Schematic diagram of the landfill reactor. 
extraction solvent (Oleic acid methyl ester OME) with similar properties but a stable composition was used.

By using a non-polar solvent, majority of the non-polar FAs were dissolved in the extraction solvent, and the polar FAs remained in the liquid phase of the bio-waste substrate.

After the extraction of the non-polar FAs into the solvent, they were re-extracted by a special extraction technology. After re-extracting the FAs from the solvent, a transesterification process was used to produce fatty acid ethyl esters, which can be sold as cleaners or solvents to the metal industry for surface treatment. The production of other bio-based products, such as lubricants, fuels and polymers, are also possible.

The generation and extraction of FAs as well as the production of bio-based products have been proven to be possible by a project involving TU Darmstadt, Eigenbetrieb für kommunale Aufgaben und Dienstleistungen (EAD), Jager Biotech and Handelshaus RUNKEL (LOEWE-Verbundprojekt 350/12-40, 2014).

\section{RESULTS AND DISCUSSION}

In this chapter, the results of the investigations with substrate from Germany and the typical substrate from Africa are presented. First, the different waste characteristics of the used substrates are given. Next, based on these characteristics, the properties of the different liquid substrates are demonstrated and discussed. The third part of this chapter shows the potential of extraction of carboxylic acids from these two substrates. Furthermore, the enhancement of the treatment by the new method is pointed out. Finally, the potentials of the different substrates are explained.

\subsection{Substrates' characteristics - German bio-waste and residual waste from Africa (Morocco)}

As explained earlier, the first experiments were performed with liquid substrates generated from biological and residual wastes from Darmstadt, Germany. Afterwards, the produced results and investigations were compared with the simulated Moroccan waste. Based on previous studies (Soudi and Chrifi, 2007), a typical residual waste of Morocco was generated by using biological and residual wastes from Germany. A comparison of both wastes is shown in the following diagram.

As shown in Figure 5, the basic compositions of the two substrates are quite similar. Both have a high amount of organic compounds, about $75 \mathrm{wt} \%$ for the African waste and $83 \mathrm{wt} \%$ for the German waste. The amount of residual waste is between 14 and $10 \mathrm{wt} \%$, and the amount of plastic is about 3.5 to $5.7 \mathrm{wt} \%$. However, there is a significant difference between both substrates with respect to the fraction of organic matter. In the used German waste, $75 \mathrm{wt} \%$ of the organic matter can be defined as green waste, while the organic fraction of the African waste consists of nearly $100 \mathrm{wt} \%$ of kitchen waste.

Also, the comparison of the dry matter content showed similar results. The German waste consists of $39 \mathrm{wt} \%$ of dry matter, while the dry matter of the African waste is 34.5 wt\%. Also, $68.5 \mathrm{wt} \%$ of the dry matter can be defined as organic in the German waste, while only $60 \mathrm{wt} \%$ of the dry matter of the African waste is organic.

\subsection{Characteristics of the liquid waste fractions}

In this subchapter, the major properties of the two liquid substrates, which were produced by the different kinds of waste previously described, are presented. Major parameters, such as $\mathrm{pH}$-value, electrical conductivity, redox potential, the sum parameter of organic acids (shown as acetate equivalents), the chemical oxygen demand (COD), the total nitrogen and total phosphorus, are analysed. The organic acids, COD as well as total nitrogen and total phosporus were analysed by quick tests of Hach Lange (LCK 365 for organic acids, LCK 514 for COD, LCK 138 for total nitrogen and LCK 348 for total phosphorus).

As shown in Table 1, the two different substrates have similar $\mathrm{pH}$-values, about 5 , and a negative redox potential, which indicates anaerobic conditions. However, the concentration of organic acids and the COD show big differences. For the German waste, on average, the COD is about $62,611 \mathrm{mg} \mathrm{O}_{2} / \mathrm{l}$, and the amount of organic acids is about

\section{Waste composition}

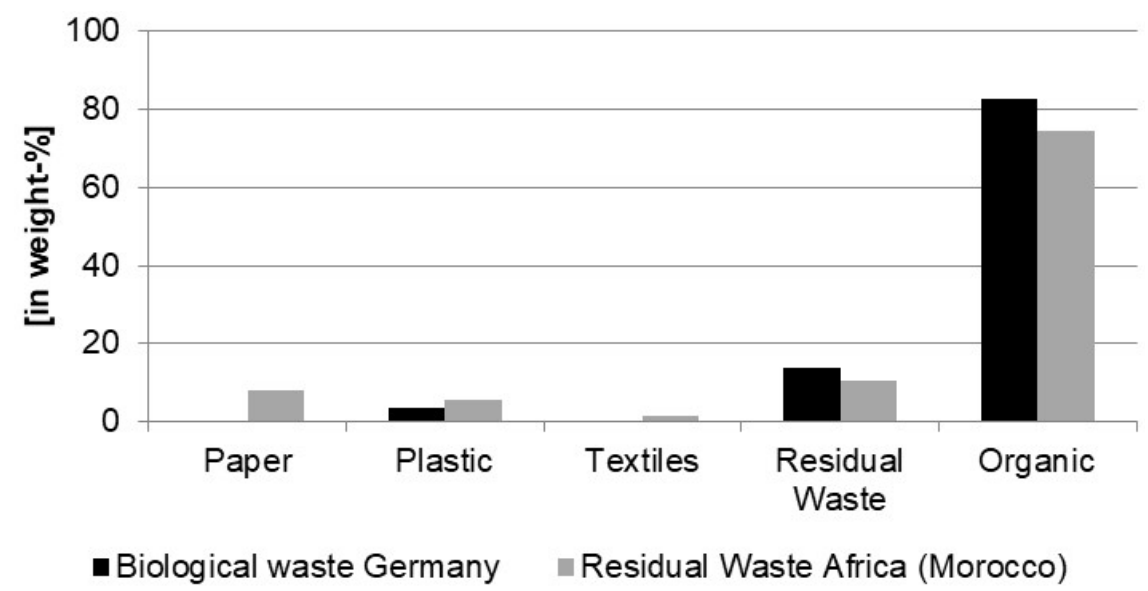

FIGURE 5: Comparison of the used wastes from Germany and Morocco. 
$20,418 \mathrm{mg} \mathrm{CH}_{3} \mathrm{COOH} / \mathrm{I}$. On the other hand, the COD of the liquid phase of the African waste and the concentration of organic acids are about $50 \%$ and $25 \%$ higher than the respective German values. These simple analyses indicate that the liquid phase produced from African waste has more organic acids, which can be used for the extraction process. German and African bio-wastes used for this study as substrates were analysed to compare total nitrogen and phosphorus values of these materials.

The results of total nitrogen show a slight difference between African and German bio-wastes. The average nitrogen concentration in the liquid phase of the German as well as African wastes is approximately $3,000 \mathrm{mg} / \mathrm{l}$ and $3,600 \mathrm{mg} / \mathrm{l}$, respectively. The range of total nitrogen in African wastes is from $2,997 \pm(45)$ to $4,243 \pm(94) \mathrm{mg} / \mathrm{l}$ with a very low relative standard deviation between 1.5 and $2.2 \%$. Total nitrogen in German wastes is in the similar range, namely, 2,997 $\pm(96) \mathrm{mg} / \mathrm{l}$.

In contrast, a significant difference was observed between total phosphorus in the African and German wastes. Total phosphorus of the African bio-wastes ranges from $7.4 \pm(0.92)$ to $323.7 \pm(106.8) \mathrm{mg} / \mathrm{l}$, whereas total phosphorus of German bio-waste reaches about $25.77 \pm$ (5.49) $\mathrm{mg} / \mathrm{l}$. The large fluctuation in total phosphorus in the liquid substrate from African wastes could result from their heterogeneous compositions of the bio-wastes fed to the reactors. Unlike German wastes, these African wastes were not homogenized and different kinds of organic wastes were used in the reactors.

The concentration of nitrogen and phosphorus of the liquid phase of these bio-wastefrom Africa and Germany is low compared to other similar substrates in Germany, like liquid fertilizers from digestion plants. The average concentration of nitrogen and phosphorus in liquid fertilizers are about 5,000 - 5,400 $\mathrm{mg}$ and 1,500 - 1,800 mg/l, respectively (BGK, 2013). However, low nitrogen and phosphorus content of our tested substrates will not inhibit the microbiological process. In order to optimize the microbiological reactions, the effect of bio-waste compositions on the microbiological reactions in the reactor could be fur-

TABLE 1: Comparison of the liquid waste phases from Germany and Africa.

\begin{tabular}{|c|c|c|}
\hline \multirow{2}{*}{ Measured Parameters } & \multicolumn{2}{|c|}{ Liquid phase from } \\
\hline & German waste & African waste \\
\hline $\begin{array}{l}\mathrm{pH} \text {-value } \\
{[-]}\end{array}$ & $5.23 \pm(0.73)$ & $5.12 \pm(0.8)$ \\
\hline $\begin{array}{l}\text { Electrical conductivity } \\
{[\mathrm{mS} / \mathrm{cm}]}\end{array}$ & $18.82 \pm(2.48)$ & $28.85 \pm(4.72)$ \\
\hline $\begin{array}{l}\text { Redox potential } \\
{[\mathrm{mV}]}\end{array}$ & $-188.42 \pm(135.3)$ & $-95,99 \pm(61.23)$ \\
\hline $\begin{array}{l}\text { Organic acids } \\
{\left[\mathrm{mg} \mathrm{CH}_{3} \mathrm{COOH} / \mathrm{l}\right]}\end{array}$ & $20,418 \pm(4,788)$ & $25,075 \pm(3,058)$ \\
\hline $\begin{array}{l}\mathrm{COD} \\
{\left[\mathrm{mg} \mathrm{O}_{2} / \mathrm{l}\right]}\end{array}$ & $62,611 \pm(15,207)$ & $95,944 \pm(24,144)$ \\
\hline $\begin{array}{l}\text { Total Nitrogen } \\
{[\mathrm{mg} / \mathrm{l}]}\end{array}$ & $2,996.67 \pm(95,68)$ & $3,620 \pm 667.67$ \\
\hline $\begin{array}{l}\text { Total Phosphorus } \\
{[\mathrm{mg} / \mathrm{l}]}\end{array}$ & $25.77 \pm(5.49)$ & $165.53 \pm(175,24)$ \\
\hline
\end{tabular}

ther investigated.

\subsection{Results of gas chromatography - mass spec- trometry (GC-MS) analyses of the liquid phases}

In this study, samples taken from the substrates were diluted in a ratio of 1:10 with Milli-Q water, and the $\mathrm{pH}$ was adjusted to 1.5 or 3.0 by adding $1 \mathrm{~N}-\mathrm{HCl}$ solution. Samples were filtered using a micro filter (WIC 80845: $0.45 \mu \mathrm{m}$ PTFE with glass fibre, WICOM, Heppenheim) before the GC/MS analysis.

The analysis was conducted with Trace GC Ultra coupled with ISQ-MS, electron ionisation (EI) as well as to TriPlus RSH liquid injection autosampler (Thermo Scientifics, Dreieich). The column used for this study was TG WAX-A (30 m; i.d. $0.32 \mathrm{~mm}$; thickness $0.50 \mu \mathrm{m}$; stationary phase: polyethylene glycol; Thermo Scientifics, Dreieich). For each measurement, $0.5 \mu \mathrm{L}$ of the sample was injected into a split/splitless injector heated at $260^{\circ} \mathrm{C}$ and analysed at a split ratio of 1:20. The GC oven programme was set as follows: at $80^{\circ} \mathrm{C}$ for $1 \mathrm{~min} ; 20^{\circ} \mathrm{C} / \mathrm{min}$ till $120^{\circ} \mathrm{C} ; 6.1^{\circ} \mathrm{C} / \mathrm{min}$ till $205^{\circ} \mathrm{C}$; at $205^{\circ} \mathrm{C}$ for $10 \mathrm{~min}$. In Figure 6 , the comparison of carboxylic acids in the two liquid waste phases is shown.

As shown, three major compounds, acetate, butanoic acid and hexanoic acid, can be found in the liquid substrates. The African waste samples mainly contained acetate (40 wt\%) and butanoic acid (36 wt\%). In the liquid phase of the German waste, the main compounds were acetate (35 wt\%) and hexanoic acid (24 wt\%).

These acid compositions could be based on the compositions of the different wastes that were used for the generation of the liquid substrates. For experiments involving African waste, kitchen waste was used as organic compounds. For Germany, organic waste mainly contained green waste, consisting of longer organic substances.

\subsection{Extraction potential and product estimation}

The liquid phase obtained from the German bio-waste underwent chain elongation with the addition of ethanol. After the addition of ethanol, the fatty acids were enlarged, as described in Equation 1.

Extraction tests on the liquid phase from the German bio-waste showed the production of acetate (about 37 wt\%), propionic acid (about $7 \mathrm{wt} \%$ ), butanoic acid (about 30 wt\%), pentanoic acid (about $15 \mathrm{wt} \%$ ), hexanoic acid (about $34 \mathrm{wt} \%$ ), heptanoic acid (about $10 \mathrm{wt} \%$ ) and octanoic acid (about 13 wt\%).

Nevertheless, the extraction procedure was done with mediums 1 and 2 of the liquid substrates. An estimation of extractable carboxylic acids and producible bio-based products using only one extraction step involving liquid waste from Germany is shown in Figure 7.

Using a single extraction step, only $20-25 \mathrm{mg}$ of MCFA could be extracted from the biological waste of Darmstadt. The following figure shows the material flows within the composting facility in order to extract these MCFA.

Based on the data, in the treatment process of the used vegetable oil and the extracted MCFA from the biological waste, about $105 \mathrm{mg}$ of bio-based product in form of a biobased fuel with bio-diesel properties was generated at the composting facility in the study carried out in 2014. 


\section{Carboxylic Acids in the liquid waste phase}

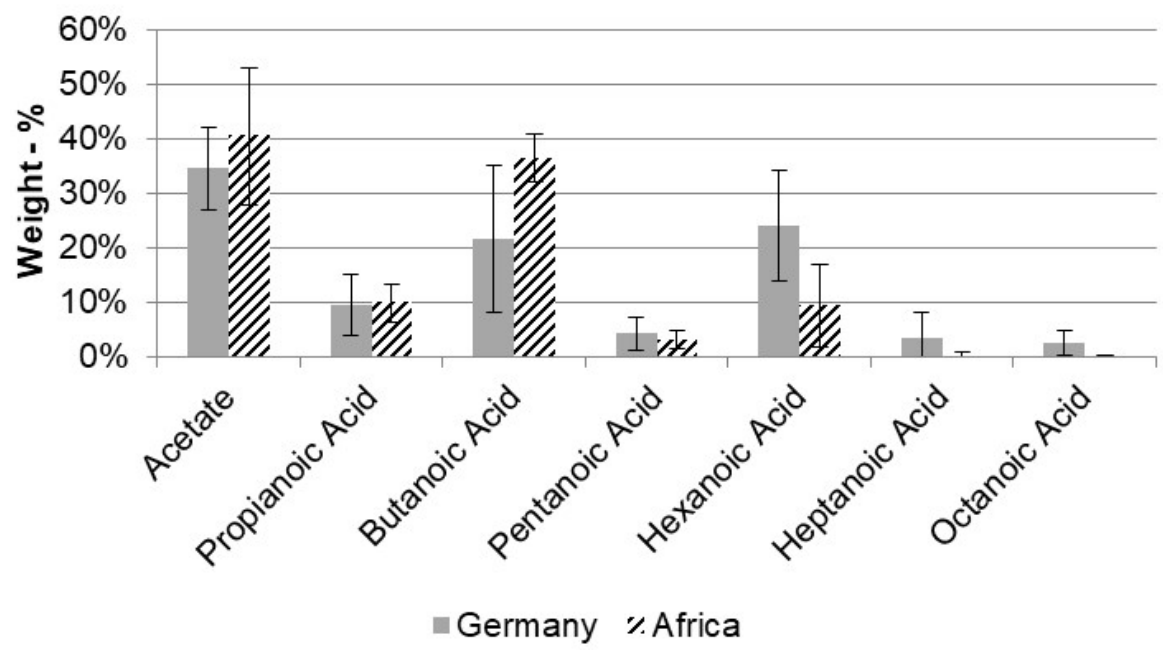

FIGURE 6: Concentration of carboxylic acids in the liquid waste phases.

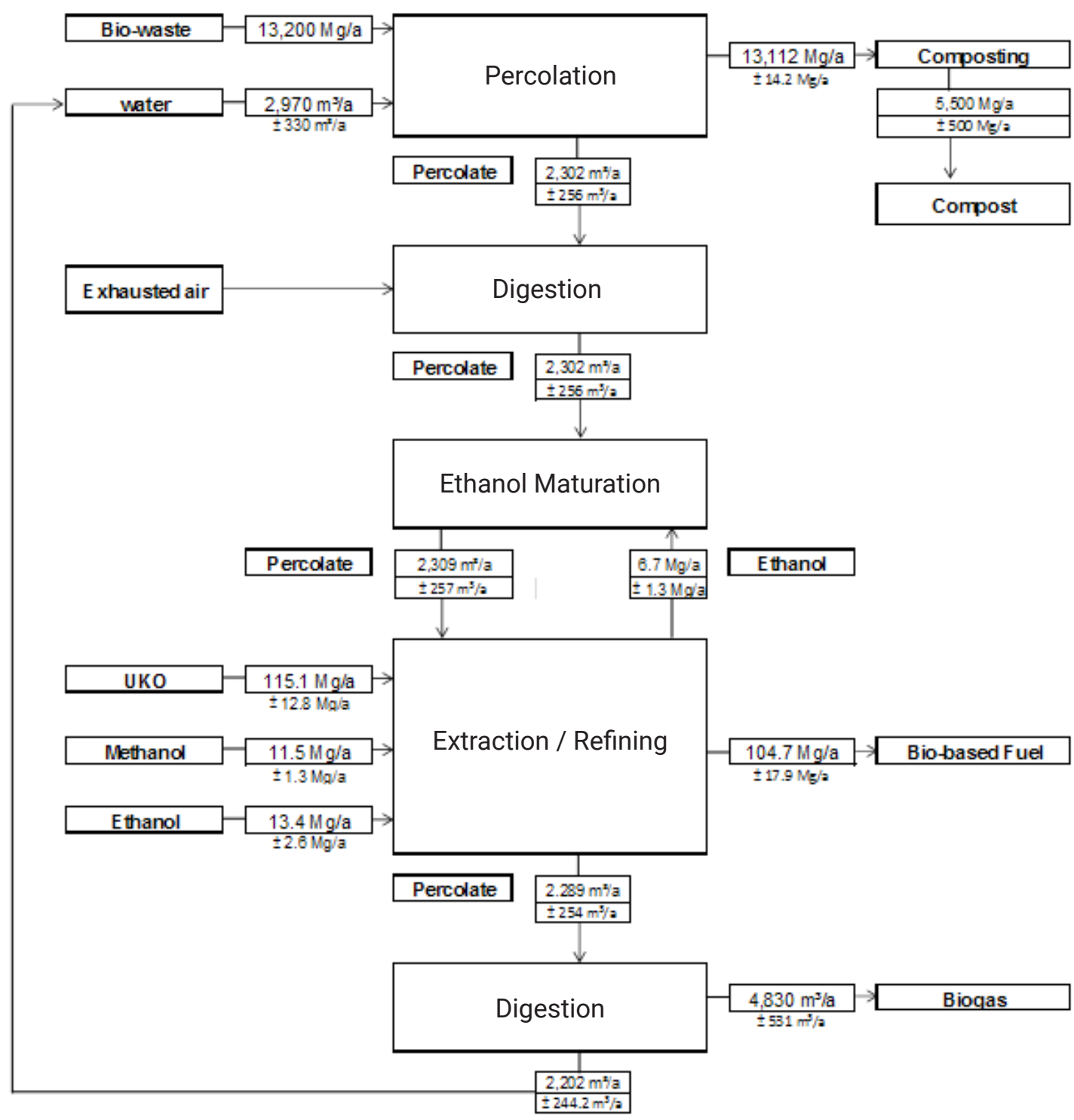

FIGURE 7: Estimated product quantities before technology optimisation .at the composting facility in Darmstadt [Kannengiesser, 2015]. 


\subsection{Results of the technology optimisation}

This chapter deals with the GC-MS analyses of the biowaste liquid phase (the percolate), the leachate and the solvent phase (OME). Because of the solubility of the fatty acids in water, only acetate and octanoic acid were analysed in the bio-waste liquid phase.

To determine the fatty acids that were changed to the solvent phase, a new GC-MS method was developed. By using this new method, non-polar fatty acids from heptanoic to decanoic acid were analysed. The examined spectrum of the MCFA was enlarged to decanoic acid in order to find out if the chain elongation process stops after octanoic acid or not.

The titration of the solvent shows only the quantity of the acids, but not the quality. In order to examine the fatty acids that are in the solvent phase, the developed GC-MS method was used.

After the first GC-MS analyses, some conspicuities were noticed in the measurements, such as column bleed, carry over or asymmetric peaks. As a result of this, the detection of the fatty acids remained difficult. Assuming that the detection of fatty acids is better at high temperatures, the GC-MS column was changed from TG WAX MS A, which is a more polar column with a maximum temperature of $250^{\circ} \mathrm{C}$, to a capillary type thermal column TR-5MS, which is non-polar, consists of $5 \%$ Phenyl methylpolysiloxane and can be heated to a maximum of $330 / 350^{\circ} \mathrm{C}$.

The analysis method was optimised for better and specific detection of FAs. First, a temperature adjustment programme was carried out. The MS transfer-line temperature and MS ion source temperature were increased. By using the new column, which can withstand temperatures up to $350^{\circ} \mathrm{C}$, a higher temperature was set.

After the separation of the fractions in the gas chromatograph at $260^{\circ} \mathrm{C}$, the fragments were transported through the transfer line into the MS. The temperature should be as high as the starting one, so no cooling was considered at this stage. The mass spectrometer tempera- ture was raised to $270^{\circ} \mathrm{C}$. The results from the German liquid waste are shown in Figure 8.

The extractive digestion took about two weeks. In Figure 8 , the acid concentrations at the beginning of the investigation and after two weeks are shown in total. The two samples were treated by the extractive digestion procedure, and as a result, both showed the same behaviour. The concentrations of the non-polar fatty acids that were dissolved in the extraction solvent increased within the two weeks. Heptanoic acid increased by about 49 wt\%, octanoic acid by about 60 to $120 \mathrm{wt} \%$, nonanoic acid by about 300 to $650 \mathrm{wt} \%$ and decanoic acid by about 100 to $300 \mathrm{wt} \%$.

Unfortunately, based on the results at this point, certain estimations about the product quantities could not be made. More extraction tests still have to be done. At the moment, the presented data just shows some trends, which have to be proven by repeating the experiments.

The following direct comparison will show the differences between the old and the new treatment processes. In Figure 9, the extraction potential of fatty acids in the percolate using the punctual method is illustrated. It also shows the comparison between the availability of FAs in the percolate before the extraction and the FAs concentration in the OME.

In total, the extraction potential of the fatty acids in the percolate was about $21.800 \mathrm{mg}$. With the old method, as described above, about $3.720 \mathrm{mg}$ of fatty acids can be extracted. Due to the polar property, the longer fatty acids had the highest extraction potential. Figure 10 shows the extraction of the FAs in the leachate. It also presents the results of the old extraction method.

The total amount of fatty acids in the leachate was about $27.700 \mathrm{mg}$, while about $4.720 \mathrm{mg}$ can be extracted. In summary, around $17 \%$ of the FAs could be extracted with the punctual extraction. The comparison results of the two extraction methods showed that the new method, which was able to extract about $7.685 \mathrm{mg}$ of fatty acid, has a $63 \%$ higher extraction rate than the old one. Figure 11 shows the extraction result using the new method. In this new extraction

\section{Concentration of carboxylic acids in the solvent phase}

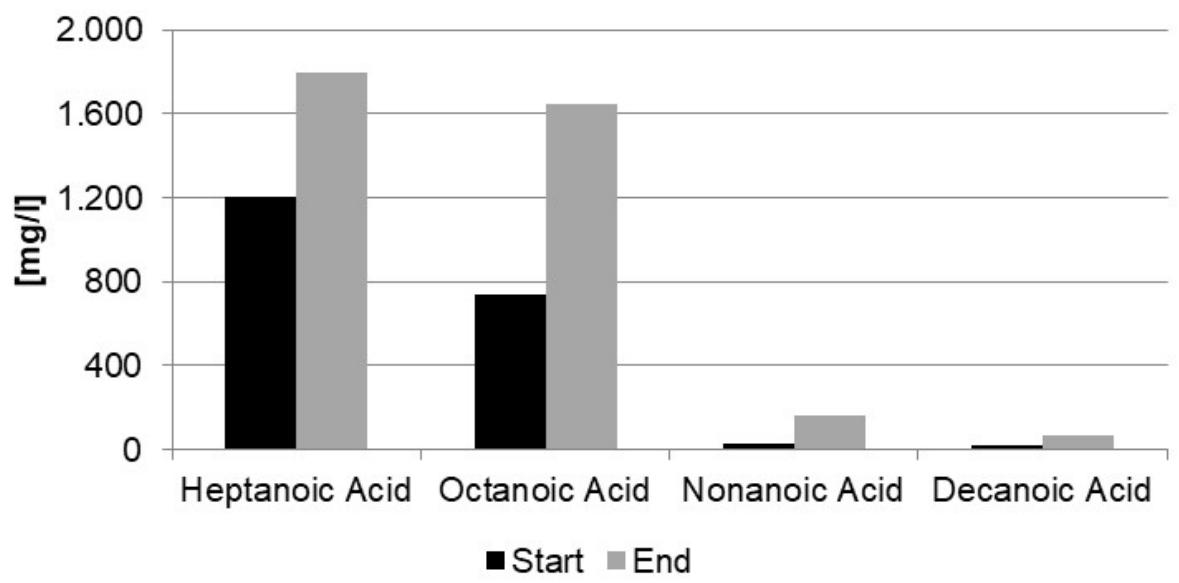

FIGURE 8: Concentration of carboxylic acids in the solvent phase from the African waste. 
process, the extended measuring method was applied. The results show the extraction of additional amounts of the fatty acids from nonanoic and decanoid acid.

According to the extension of the residence time of the extractant, it is possible to enhance the amount of non-po- lar FAs. This is as a result of the chain elongation during the ethanol maturation. The extraction values are twice as high as those previously present in the liquid.

On average, the dissolved MCFA have 8 carbon atoms, and approx. $82 \mathrm{mmol}$ MCFA were dissolved in one liter of

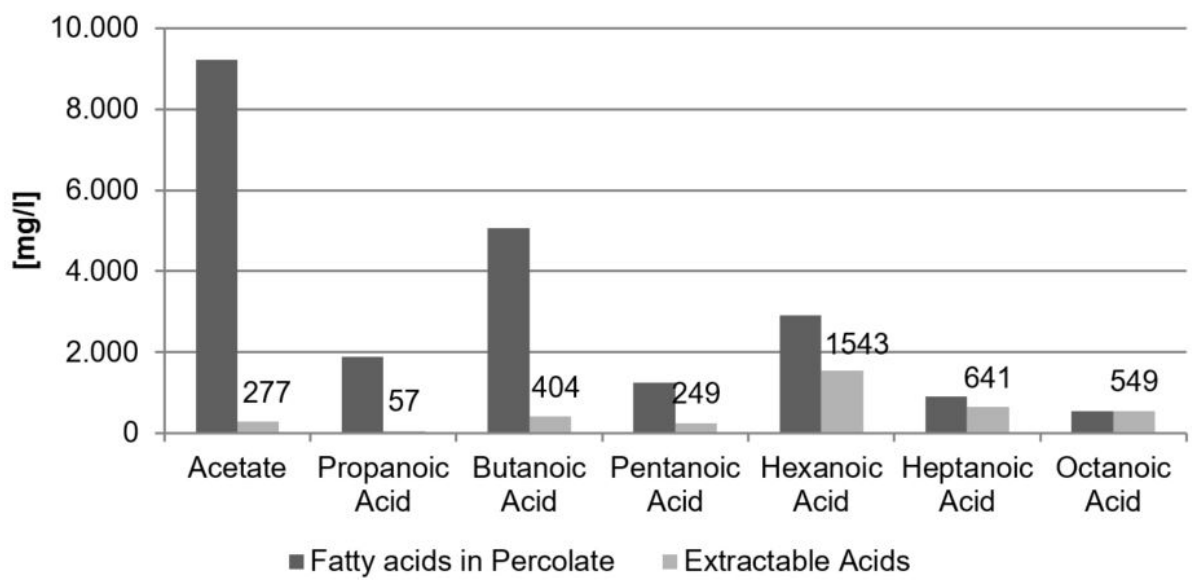

FIGURE 9: Fatty Acids and Extraction Potential from Percolate (old extraction method).

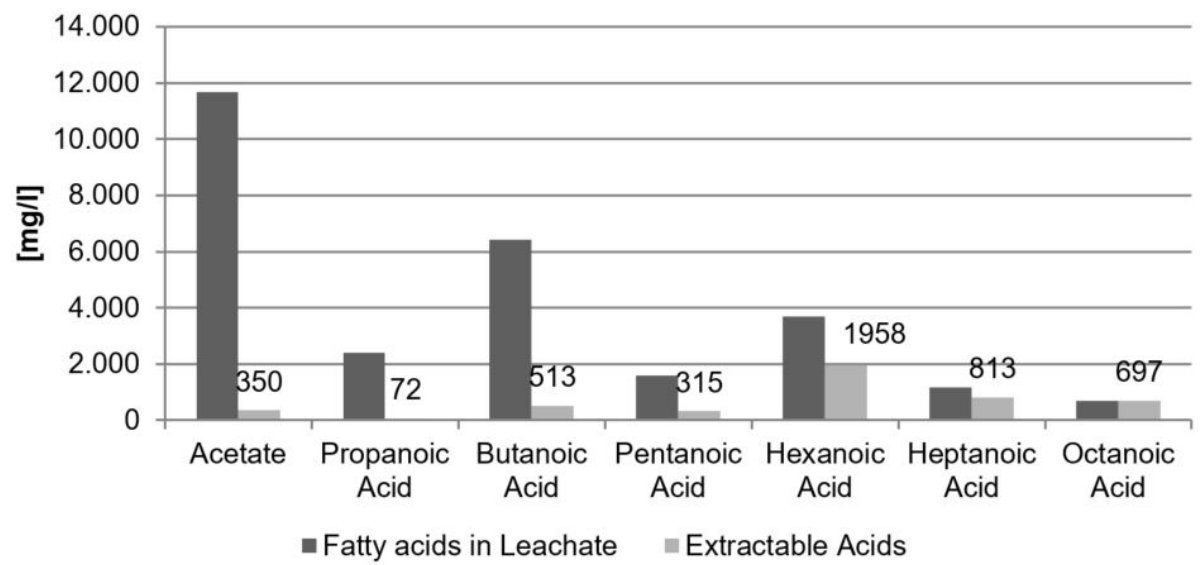

FIGURE 10: Fatty Acids and Extraction Potential from Leachate (old extraction method).

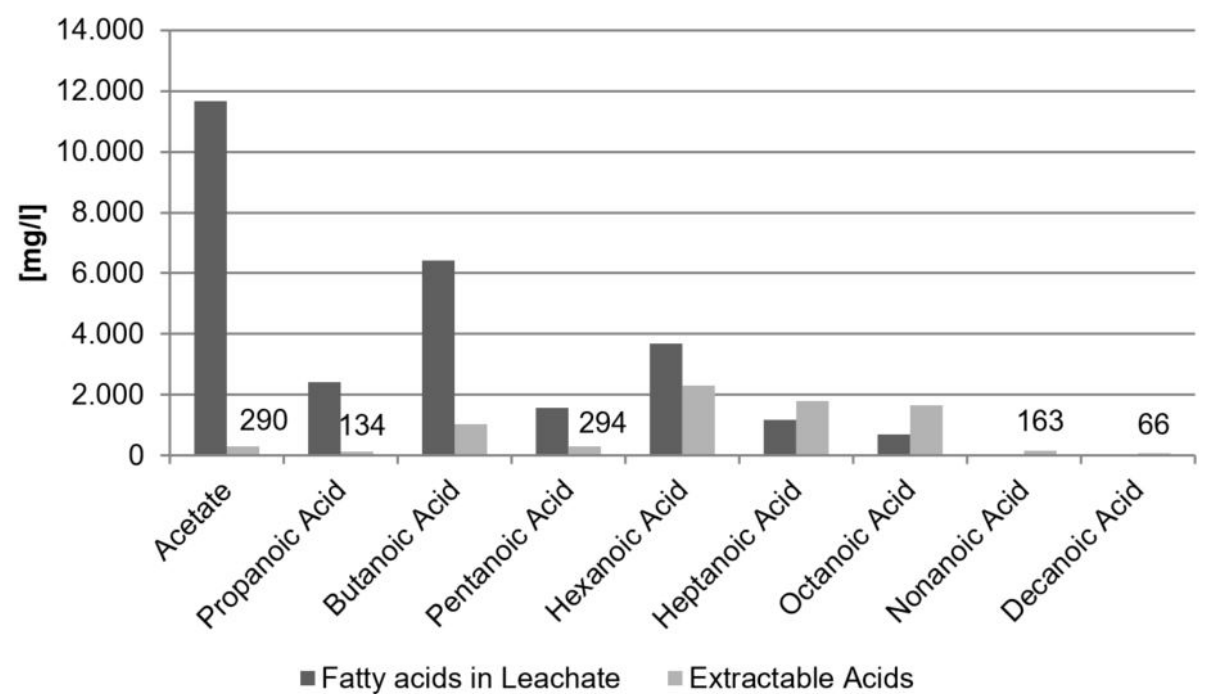

FIGURE 11: Fatty Acids and Extraction Potential from Leachate (new extraction method). 
OME. The GC-MS analysis shows that MCFA with more than 8 carbon atoms were produced and extracted. This leads to the impression that the chain elongation process, described in Equation 1, does not stop with octanoic acid. The chain elongation process can also be used to produce longer chains of fatty acids, such as decanoic acid or even longer ones.

\subsection{Comparison of the different liquid phases}

Hereinafter, the first analysis results will be displayed. All liquid samples were analysed, and their fatty acid potentials were examined. The fresh pressed off water from organic waste will be shown. Apart from that, the liquids of the digestion and the leachate of different ages are introduced.

In Figure 12, the fatty acids concentration of the water from pressed organic waste is illustrated. In addition to the conditions at the start of the investigation, the concentration distributions at the end are also shown. It was observed that the fatty acids variation was limited to acetate and propionic acid at the beginning. After the maturing phase, longer-chain fatty acids were produced in higher quantities. This led to a reduction in acetate and an increase in butanoic acid due to the chain elongation. The rapid increase is partly due to the ethanol maturation of fatty acids. However, it should also be noted that this very fresh pressed off water has not been pre-treated and the biological decomposition took place over the storage period. During the storage of the substrates, the organic substances were degraded and the process of generation of the fatty acids began.

Figure 13 presents the different phases of the digestion plant. Based on the comparison of the different liquids' concentrations, a clear conclusion can be drawn. The percolate obtained after the pre-rotting process had the highest extraction potential. With around $11.000 \mathrm{mg} / \mathrm{l}$ acetate, it had a 24 times higher concentration than after the fermentation. After the pre-rotting in the facility, the condition of the liquid could be estimated as good. As a result, the material was not suitable for further processing after fermentation. The fatty acids were almost completely converted into methane and $\mathrm{CO}_{2}$ during the anaerobic process.

Figure 14 shows the measured fatty acids concentrations in the leachate of the Moroccan waste. A distinction is made between the results after about 3 months of storage of the waste under partially anaerobic conditions and after a maturation period of about one year. The development of the fatty acid lengths can be seen here. A higher enrichment of around $60 \%$ butanoic acid was observed after one year, while acetates were reduced by almost $50 \%$. A small increase was noted for octanoic acid. Due to the waste mixture and the incomplete anaerobic conditions, only a slow decomposition of the organic components occurred in the simulated landfill.

The leachate from German landfills has a very low organic potential. As described earlier, only a small amount of organic waste is deposited in Germany. With a $\mathrm{pH}$ value of about 7, it is in the neutral range. Also, the redox potential with positive values does not indicate a high organic activity. This is also confirmed by the general organic acid content of $278 \mathrm{mg} / \mathrm{l}$. Compared to the values in Table 1, these are only $1 \%$ of the value measured in the percolate. Only small amounts of acetate and butanoic acid from 50 up to a maximum of $800 \mathrm{mg} / \mathrm{l}$ were generated. According to these results, even further tests for the maturation of the leachate show no potential.

\section{CONCLUSIONS}

The investigation of the different waste substrates indicates clear results. The process started with percolates from biological waste after anaerobic treatment. Subsequently, further processes were conducted to evaluate as well as implement the previously tested maturation and extraction method on other liquid waste substrates. In summary, it was noted that not all percolates from organic materials are well suited for this processing method. For example, the percolate from fresh waste must first be pre-treated in order to provide ideal conditions for the subsequent improvement in fatty acid generation.

However, it was established that the leachate from household waste was suitable for the experiments. The young landfill leachate extracted from simulated landfill sites also showed a high organic potential. The difference from organic household waste can be attributed primarily to the high proportion of kitchen waste. Short-chain carboxylic acids were present in higher quantities at the start of the experiments. Also, in this regard, ethanol maturation with subsequent extractive digestion was implemented after separation of the leachate.

\section{OUTLOOK}

In order to optimise this new bio-technology and integrate it into the existing biological waste treatment facilities, more investigations and analyses have to be done. The new treatment step, called extractive digestion, has a high potential to improve the quality and quantity of extractable non-polar fatty acids from bio-waste substrate. The first titrations and the GC-MS analyses show that the quantity of extracted non-polar fatty acids is much higher when extractive digestion is applied than without the use of this method. In order to perform some representative calculations, more analyses of the liquid phase and the solvent phase by GC-MS are needed.

A second important step is the optimisation of the bio-technology in order to extract the longest producible fatty acids (nonanoic and decanoic acid). The extraction of these fatty acids and the generation of bio-based products will make the productivity range of the facility higher and wider as well as make its $\mathrm{CO}_{2}$ emissions lower.

In addition to these experiments, new tests should be carried out to examine the amount of solvent that is needed to extract the optimal amount of non-polar fatty acids from the liquid phase of bio-waste in the sense of sustainability (social, economic and ecologic conditions).

The experiments involved in extractive digestion were only done on the lab scale. In order to prove the practical use of this method in treatment facilities, tests in the relevant environment have to be carried out. 


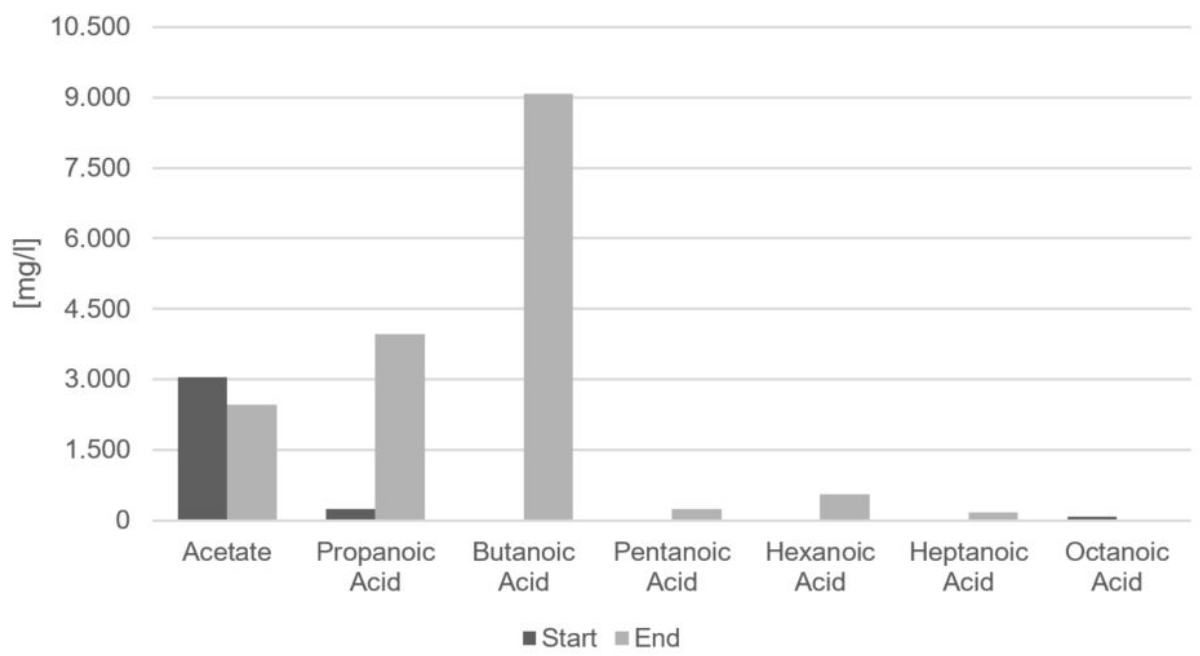

FIGURE 12: The comparison of fatty acids in the pressed off water samples at the start and end of the treatment process.

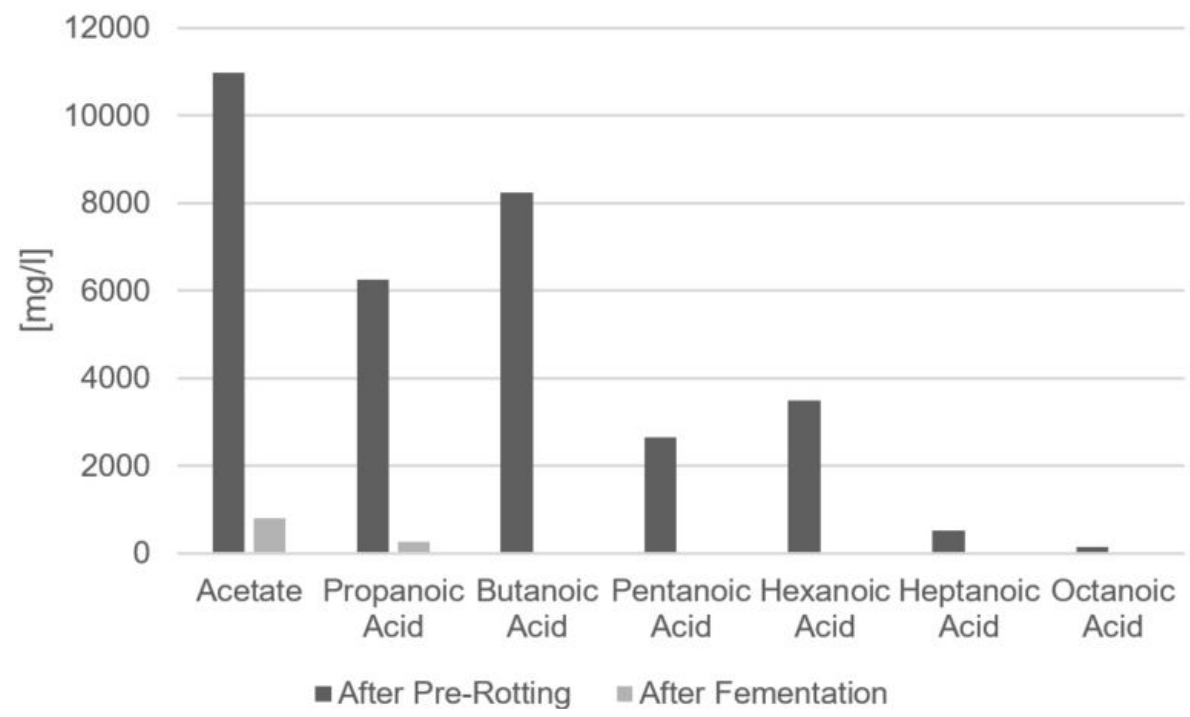

FIGURE 13: Fatty Acid concentration of different treated liquid samples from a digestion plant.

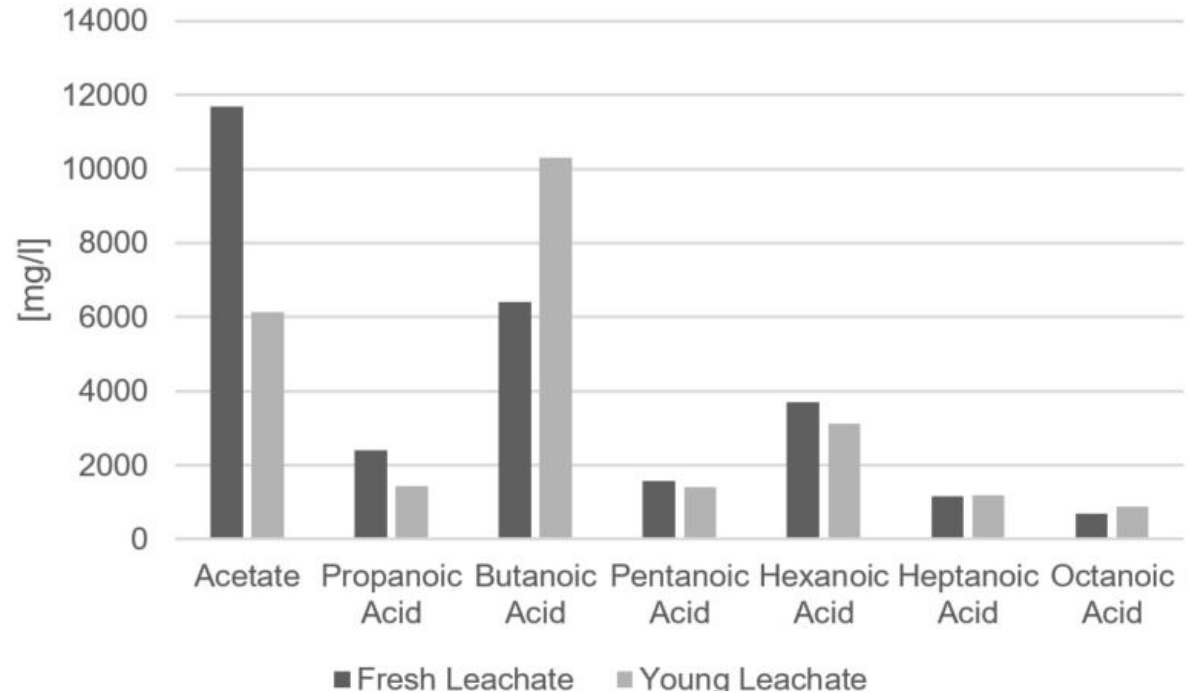

FIGURE 14: Fatty Acid concentration of the fresh and young leachate from the simulated Moroccan waste. 
The experiments involving leachate from municipal waste dumps must also be further conducted. Old leachate from existing landfills must be investigated to determine its real potentials. The added value of MCFA should be determined using adapted examination conditions and maturing methods.

\section{AKNOWLEDGEMENTS}

The results of this paper are part of the project "Knowhow transfer in waste management for developing new biotechnology applications in developing countries", which is sponsored by the German Federal Ministry of Education and Research (BMBF) in cooperation with the German Academic Exchange Service (DAAD). We would like to thank our project partners for the good ongoing collaboration. Special thanks to the two Moroccan Universities University Abdelmalek Essaadi (Tétouan), University Cadi Ayyad (Marrakech) and the Ivorian University Nangui Abrogoua (Abidjan).

\section{REFERENCES}

Andreottola, G., Ragazzi, M., Foladori, P., Rada, E. C. (2012): The unit intregrated approch for OFMSW treatment. In: UPB Scientific Bulletin, Series C: Electrical Engineering 74(1):19-26.

BmJV - Federal Ministry of Justice and Consumer Protection (2012): Legislation on the advancement of the recycling economy and securing environmental friendly waste disposal (KrWG).

BGK - Bundesgütegemeinschaft Kompost (Federal Community of Composting) (2013): Datengrundlagen - zum Beitrag „Organische Dünger in der Landwirtschaft" (data basis - contribution „organic fertilizers in agriculture). Available at: https://www.kompost.de/ fileadmin/docs/Archiv/Aktuelles/Datengrundlagen_-_Organische_ Duenger_in_der_Landwirtschaft.pdf (Retrieval date: 30.10.2018)

Bornstein, B.T., Baker, H.A. (1947): The energy metabolism of Clostridium Kluyveri and the synthesis of fatty acids. In: J.Biol. Chem., 1948 Feb; 172(2):659-669.

De Jong, E., Higson, P., Walsh, P., Wellisch, M. (2012): Bio-based Chemicals: Value Added Products from Biorefineries. IEA Bioenergy Task42 Biorefinery. http://www.iea-bioenergy.task42-biorefi neries.com (Retrieval date: 10.09.2018)

Destatis Federal Statistical Office (2018a): Environment. Waste Balance (Waste generation/remaining, waste intensity, Waste generation by economic sector)

Destatis Federal Statistical Office (2018b): Environment. Waste Management. Subject series 19, row 1.

Edwards, J., Othman, M., Burn, S., (2015): A review of policy drivers and barriers for the use of anaerobic digestion in Europe, the United States and Australia, Renewable and Sustainable Energy Reviews, 52, pp. 815-828
Fair, J. R., Humphrey J. L. (1983): Liquid-liquid extraction process. In: Fifth Industrial Energy Technology Conference Volume II, Houston, TX, April 17-20

Hoffmann, M. (2011): Konversion eines Kompostwerkes und Generierung von selektiven Vergärungsprodukten. In: Series IWAR 216: Biobasierte Produkte und Energie aus Biomasse. Publisher: Association for the promotion of IWAR, ISBN:978-3-940897-13-8, Darmstadt, Germany

Hoffmann, M. (2012): Abfalltechnische Erweiterung von Bioabfallbehandlungsanlagen für die Herstellung biobasierter Produkte. Dissertation. Publisher: Association for the promotion of IWAR der TU Darmstadt e.V., Series IWAR Number 218, ISBN 978-3-940897-16-9

Jager, J.; Rohde, C. (2006): Semizentrale Ver- und Entsorgungssysteme für urbane Räume Chinas. Final report of Chair of Water Supply and Groundwater Protection, Chair of Wastewater Technology, Chair of Waste Technology and the chair for Spatial and Infrastructure Planning, BMBF-Reseachreport, FKZ 02 WD0607

Kannengießer, J., (2015): Nutzung biologischer Siedlungsabfälle zur Generierung biobasierter Produkte und Kraftstoffe auf Basis von mittel- und langkettigen Fettsäuren - Feldstudie am Beispiel eines Kompostwerks (=Series IWAR 230). Darmstadt, Germany 2015

Kannengiesser, J., Sakaguchi-Söder, K., Mrukwia, T., Jager, J., Schebek, L. (2015): Extraction of medium chain fatty acids from organic municipal waste and subsequent production of bio-based fuelsIn: Waste Management (2015), http://dx.doi.org/10.1016/j.wasman.2015.05.030

Krause, P., Oetjen-Dehne, R., Dehne, I., Dehne, D., Erchinger H. (2014): Mandatory implementation of the Separate collection of biowaste. Environmental Research Plan of the Federal Ministry for the Environment, Nature Conservation, Construction and Nuclear Safety

Levy, P.F., Sanderson, J.E., Kispert, R.G., Wise, D.L. (1981): “Biorefining of biomass to liquid fuels and organic chemicals". Enzyme Microb. Technol., 3, P. 207-215

Mahmud, K., Hossain, M. D., Shams, S. (2012): Different treatment strategies for highly polluted landfill leachate in developing countries. In: Waste Management 32, 2012, 2096-2105

Noack, W. (1955): Biogas in der Landwirtschaft. Publisher: Otto Elsner publishing company Darmstadt, publisher number 5529, Darmstadt, Germany

Reinhold, F. (1949): Energiegewinnung aus Abfallstoffen. In: Health Engineer - Journal for Applied Hygiene and Health Technology in City and Country, 70. Year, Magazine 17/18, Page 309, Publisher: Leibniz Verlag, Munich, Germany

Rohde, C. (2007): Milchsäurefermentation von biogenen Abfällen; Dissertation, In: Series IWAR 186, Publisher: Association for the promotion of IWAR, Darmstadt, Germany

Smahi, D., Fekri, A., Hammoumi, O. (2013): Environmental Impact of Casablanca Landfill on Groundwater Quality, Morocco. In: International Journal of Geosciences, 2013, 4, 202-211

Soudi, B., Chrifi, H. (2007): Options de gestion des déchets solides municipaux adaptées aux context des Pays du Sud. Rabat- Agdal, Maroc

Thauer, R.; Jungermann, K.; Henninger H.; Wenning J.; Decker, K. (1967): „The Energy Metabolism of Clostridium Kluyveri“.European Journal of Biochemistry 4, P. 173-180 